\title{
Toward Resilient, Inclusive and Vital Technological Infrastructures for the Energies of the Landscape
}

\author{
Filippo Angelucci*
}

\author{
Università degli Studi “G. d’Annunzio" di Chieti-Pescara, Department of Architecture, Viale Pindaro, 42, \\ 65127 - Pescara, Italy
}

\begin{abstract}
Today, the implementation of energy infrastructure needs a complex "dialogue" between two apparently different aspects: technical aspects that characterize the processes of production and transformation of energy for the territory, and socio-ecological aspects related to the biological, organizational, and economic variables for cultural, creative, and productive energies of the territory.

This new dimension of designing and building the energy infrastructures replaces to the classic esthetical idea of the landscape an integrated vision of human habitat in which innovations play a key role for the redefinition of relationships between téchne, bios and oikos.

On these subjects, this article proposes a reflection on a methodological approach to re-think energy infrastructures as technological-environmental interfaces between land resources, energy needs, living dynamics, and inhabiting practices of territories and cities. Four possible scenarios are presented starting from some research experiences developed on Italian Abruzzo region. Through these experiences, emerges a new strategic, tactic and operational framework for the design of energy infrastructures. A new design framework in which energy infrastructures can contribute to re-build relations and connections between the acceptance/correlation of technological innovations and resilience, inclusiveness and vitality of the landscape.
\end{abstract}

Keywords: Resilience, Inclusiveness, Vitality, Energy Infrastructure, Technological Design.

\section{INTRODUCTION}

Numerous interpretations have been made of the sustainability of human social and territorial development and the need for technical innovations to support the energy-related elements of this process. The results have often exposed antithetical positions between the supporters of unlimited change to inhabited spaces and the staunch defenders of the conservation at all costs of landscapes inherited from the past.

The continuity between tradition and innovation in the field of building technologies and the forms of developing infrastructures providing energy to the human habitat, both past and present, constitute and define elements of vital importance to socioeconomic equilibriums and the strong identity of the territory.

Today, however, the organisation of urban and territorial areas is witness to widespread and growing increases in local energy consumption (for residential, tertiary and mobility activities), coupled with a parallel exhaustion of non-renewable natural resources (often delocalised and consumed to produce energy). This situation is also witness to the twilight of the modern myth of the infinite reproducibility of mechanisms for

*Address correspondence to this author at the Università degli Studi "G. d'Annunzio" di Chieti-Pescara, Department of Architecture,Viale Pindaro, 42, 65127 - Pescara, Italy;; Tel: +39.085.45.37.332; Mob: +39.339.52.38.222; E-mail: filippo.angelucci@unich.it, filangel@alice.it transforming the Earth's natural resources and the equally infinite capitalisation of short-term profits.

Faced with these global and local changes, the comparison between choices affecting processes that modify the territory and its dynamics of procuring energy appears to collapse the historic distinctions between progressive and conservative positions [1].

Neither the re-proposal of the city/territory as an infrastructural "machine" for living and producing energy, nor the conservation of the pure forms of premodern landscapes (without energy infrastructures), is sufficient to break free of the logics of unlimited development and total human domination over nature.

The human habitat of the future, based on a vision of energy sustainability, must once again become a point of convergence between natural and anthropic factors for reproducing social and economic ecosystemic equilibriums.

A renewed consideration of how we use technical resources to generate/share energy, and their effects on the modification and valorisation of the human habitat, is now the number one priority for an innovative re-reading of the relationship between energy, infrastructures, and forms of the landscape.

We must explore the possibility to reasonably employ technical resources to produce energy from the 
territory and promote the energies it offers (social, productive, cultural) in order to initiate a process which may generate poetic synergies between the biological and anthropic dimensions of the human habitat.

\section{Toward a Technological-Environmental Redefinition of Energy Infrastructures}

Viewed within the more general framework of the climatic-environmental and economic-productive issues characteristic of our contemporary era, energy-related issues require a different notion of the landscape and a diverse perception of the energy implications/relations between inhabited space and the environment.

This cultural shift comports two aspects of innovation that directly involve the role and use of technologies in the design of energy infrastructures.

An initial aspect can be linked to design research investigating the possible horizons of acceptance of technical innovations in the field of energy infrastructures to redefine symbolic-functional relations with aspects of everyday life. This involves the investigation of the possibility to establish emotional ties between users and technological innovations through actions that facilitate not only a visual, functional and productive integration with the territory, but also a spatial and administrative link with the material and immaterial elements of the system of settlement [2-4].

A second aspect is to be found in design experiments exploring the new dimensions of correlation between the different levels of energy present in the manmade environment. In this second case, energy infrastructures lose their traditional connotation as interventions overlapped on the territory based on the modernist logic of the progressive stratification, above and below the ground, of electrical networks, cabling and conduits that have no relations with context. Energy infrastructures must instead be placed within the vaster framework of connections with local uses of materials, natural resources and the movement of people and goods $[5,6]$.

These two emerging aspects generate a rupture in the technical vision of the relationship between energy infrastructures (EI) and the territory (EI as the domination of technique over nature). At the same time, they also help overcome the refusal of infrastructural projects for energy (negated El or the return to a nostalgic condition without energy). What is visible instead is the passage toward an idea of $\mathrm{El}$ as a "technological-environmental system" founded on the hybridising and co-evolutionary potentialities of transformations of the habitat and the reconstruction of lost relations between téchne, bios and oikos.

In many recent design experiments exploring the theme of the relationship between energy infrastructures and the territory, the acceptance and correlation of technical innovations are the foundation of a diverse relational notion of the design of the landscape, determining a technological-environmental evolution of the idea of El.

At least four branches of experimentation can be identified in this sense.

One branch involves the search for the communicative potentials of energy infrastructures, through $\mathrm{El}$, in order to assign them more than simply economic values and identify new codes of communication for revealing the added values of the culture of sustainability. It is an operative field in which El serve to patiently reconstruct the interrupted ties between traditional and modern building know-how.

A second branch of design research looks at the multiple identities of energy in the field of construction. They can be condensed, connected, and channelled in an El to recompose the social and ecological dynamics/cycles of the territory typical of the complexity of settlement processes.

A third branch deals instead with the possibility to exploit the realisation of an El as an occasion for constructing new energy communities of users, moving beyond the specialised notion of infrastructural works and privileging the innovative reorganisation of the habitat toward a shared and responsible use of energy resources.

A fourth branch of current research deals with the definition of hyper-landscapes of energy as settlements in which to re-find the logics of human settlement through an integral reconfiguration of $\mathrm{El}$ as complex systems used to construct new poetic synergies between the biological and anthropic dimensions of the landscape.

\section{New Definitions of Sustainability for Energy Infrastructures}

Throughout the evolution of the human habitat, the construction of infrastructures for the production and transportation of energy has modified the functions and morphologies of the constructive, urban, and natural 
components of the landscape at diverse scales. Providing access to energy resources has contributed to the progressive configuration of systems of settlement. This close relationship between energy, technologies, and landscape has often been expressed in harmony with the ecological dynamics of place. In other cases, it has emphasised the incessant advancement of technological-scientific innovations or their opposites [7].

While the acceptance and correlation between technological innovations certainly define new branches of design explorations in favour of the symbiotic co-evolution of energy infrastructures and the landscape, it is however necessary to capture other important aspects characterising what may be the dawn of a second phase in the culture of environmental sustainability.

The challenges raised by sustainability assume an even greater complexity when we consider the evident signs of reductions in non-renewable resources, increasing climate change, a general economic impoverishment of territories, and the scarcity of food resources. To this, we must add the exclusion of evervaster sections of the population from the minimum conditions of welfare, liveability and access to local resources. It is no longer sufficient to work with the ecological, economic, and social sustainability of single built objects. The time has come to adopt an integrated vision of design able to manage and orient relations between functions, flows and dynamic cycles involving the buildings, spaces and networks of the territory [8].

This new challenge introduces original definitions of sustainability that directly involve also the methods of designing EI. They become systems of interconnections between the generation and transportation of energy for the territory (and the communities inhabiting them) and the evolution of settled spaces in order to enable, care for and cultivate the cultural, productive, creative and social energies of the territory. These innovative definitions, which integrate the paradigm of sustainability without substituting it, may be linked to:

- the culture of resilience, which has led to a progressive re-definition of the built habitat as a complex socio-ecological [9], socio-technoecological [10], ecological-projective [11] and evolving/adaptive system [12]. According to recent definitions of resilience, artefacts and thus El must generate the capacity to determine the reactivity of natural resources, the adaptability of communities and the ability/health of users, the evolutionary nature of organisations and the transformability of inhabited spaces in response to sudden natural, climatic, health-related or humanitarian events/shocks [13];

- the culture of inclusion which attributes to the material and immaterial components of the built habitat and thus also to buildings, cities, open spaces and infrastructures the capacity to heighten or lessen the sustainability of the activities and participation of all inhabitants, without limitations, exclusions or standardisations [14]. In this area, the role of El exceeds the traditional functions of procuring energy to become complex components with the ability to enable and disenable the energies of a territory;

- the culture of the vitality of the built habitat, which examines not only the availability of physical resources offered by inhabited space, but also the immaterial and fluid resources of the territory. El can thus generate conditions for the production, regeneration, use and recovery of natural/artificial capital and the organisation and expression of social, cultural, technical, religious identities of communities and individuals. El thus assume a central importance as complex systems that interact and integrate traditional and more innovative infrastructural networks (green, blue, and grey networks, etc.) [15].

Resilience, inclusion and vitality considered as the new vectors of a more mature approach to environmental design focused on achieving objectives of sustainability in the short-term and medium-term. Moreover, they also place El within a framework of intervention that must focus attention on the sociocultural aspects of the built environment and its biophysiological components. This means operating with material/relational and immaterial technologies in order to define strategies, tactics, scenarios and operative actions that transform the landscape, foreseeing the possible capacities to adapt to environmental emergencies.

\section{A Hybrid and Co-Evolutionary Vision of Energy Infrastructures}

The questions analysed so far reveal the need to reconsider energy variables as the principal generators of an idea of the landscape in which El assume a dual role. Their social, ecological, and economic outcomes 


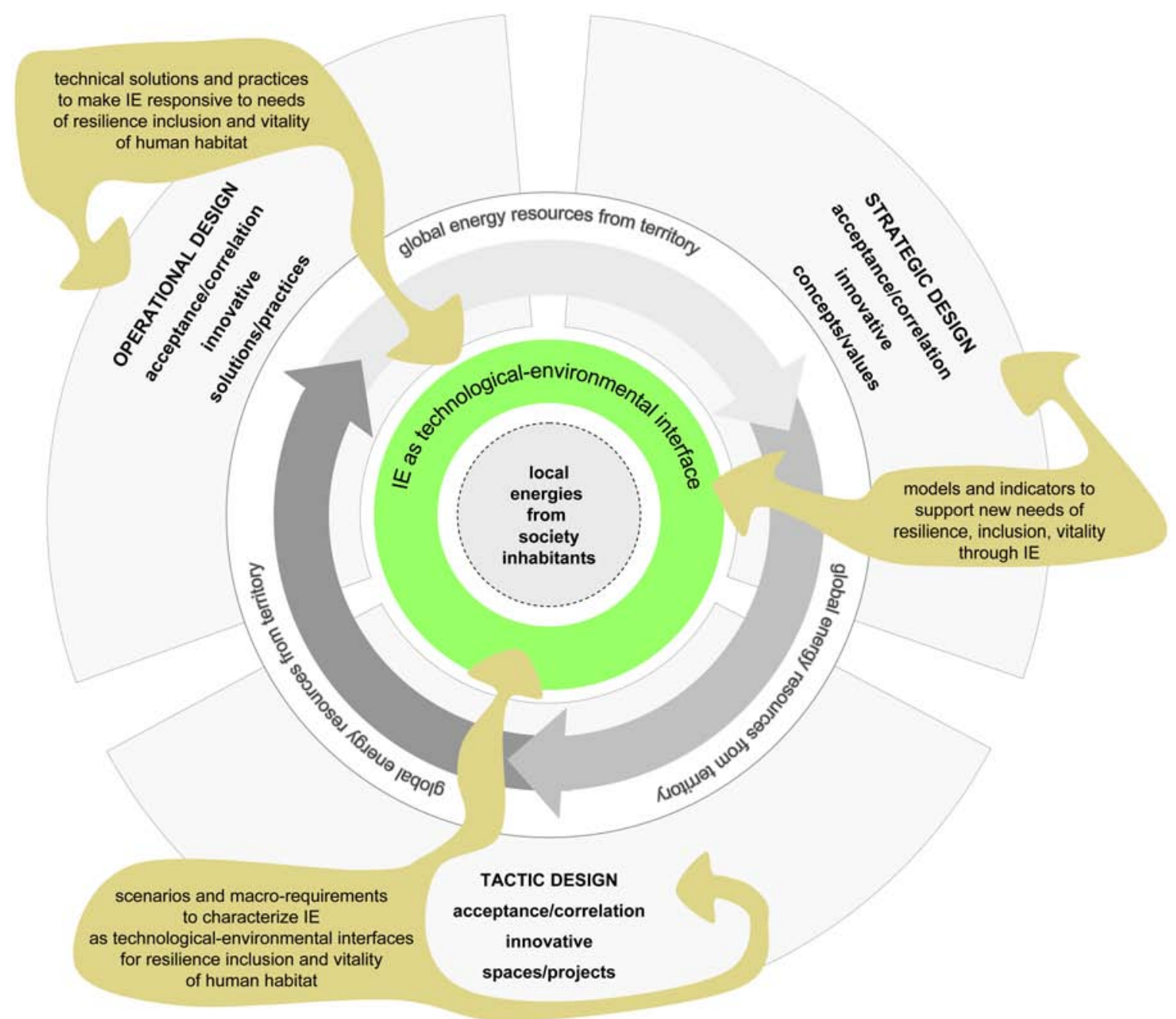

Figure 1: Integrated approach to rethink energy infrastructures as technological-environmental interfaces. Author: F. Angelucci.

give them the power to make technical innovations acceptable and comparable within the framework of material and immaterial cultures of inhabiting a territory. At the same time, they can help satisfy the new needs for resilience, inclusion and vitality characterising the evolution of a sustainable culture of dwelling. The technological-environmental nature of El exists precisely in the relationship of acceptance/ correlation between technical innovations in the energy sector and the resiliencelinclusion/vitality of the human habitat (Figure 1).

In light of these considerations, El must foster interaction between the behaviour and decisions of users and designers to heighten the acceptability of innovative technical actions correlated with the physical characteristics of the habitat. In so doing, they can trigger the formation of new material scenarios of inhabiting (e.g. spaces for sharing energies, localised micro-generation, and development of the creative energies of inhabitants) [16, 17]. All the same, El must likewise be reconsidered as systems that interact also with the spatial dimensions of the built habitat (natural, private, public, collective, residual spaces). These can be dimensions in which to channel, cultivate, and generate less tangible aspects that may, however, give rise to innovative immaterial scenarios of inhabiting (e.g. shared management of resources and spaces, the transformation of inhabitants from simple users into prosumers [18], the multi-tasking use of spaces).

Energy infrastructures thus become a complex technological-environmental artefact that serves to:

- reconnect methods of production, use, transformation and economic management of space and resources in order to satisfy the needs of a constantly evolving community [19];

- reactivate the motility of natural physicalbiological processes and cyclical conditions (water, air, carbon) able to guarantee the 
maintenance of ecosystemic functions for current and future generations [20];

- $\quad$ restore a "relativity" between settled communities and the physical reality of the territory in order to reconstruct relations, dependencies, equilibriums and circuits involving the space, time, energies, natural and artificial components of the territory [21].

This convergence between the material and immaterial aspects of inhabiting introduces a different spatial, functional, and morphological notion of energy infrastructures, which must assume a new hybrid and co-evolutionary nature.

Two important conceptualisations moving in this direction should be incorporated within the design of EI as complex technological-environmental systems [22].

The first involves the possibility of rethinking $\mathrm{El}$ as green infrastructures, referring to the broadened vision attributed to this type of infrastructure in recent years (European Strategy for Sustainable Development/2011, Technical Annex to EU/COM 249/2013) [23]. This approach links the idea of ecologically oriented infrastructures (i.e. the efficiency of natural resources, mitigation of climate change, disaster prevention, soil and water management) to a vision increasingly more open toward the social aspects of the territory (i.e. low carbon transportation and energies, activities of agriculture and forestry, health, tourism, the resilience of settlements). The consequence of this approach is the transformation of El into eco-social networks [24, 25].

The second notion refers to a vision of the contemporary landscape as a system resulting from the dynamic equilibrium between the management/protection of existing resources and innovations necessary to make the landscape hospitable and inhabitable. This places El within a vaster project that involves the resources and energies of the entire territory (natural, rural, urban, exceptional, daily, abandoned spaces) [26]. It is important not to "freeze" the landscape, but instead to complement its changes with interventions that involve, also and above all, interstitial spaces, residual areas, decommissioned infrastructures, and parts of the city and territory left unresolved in the wake of the modern culture of limitless growth [27].

Confronting this twofold challenge to design means adopting new methodological approaches that operate at different scales, models, requirements, and actions of intervention. It also means assuming the capacity to identify El within vaster and inter-systemic design scenarios that serve to establish a coexistence between the components of various systems to be partially conserved and/or modified.

\section{El as Technological-Environmental Artefacts}

Achieving the design objective of reconsidering $\mathrm{EI}$ as technological-environmental artefacts is fundamental for facing the issues of sustainability triggered by the current phase of transition from modern/industrial landscapes to post-industrial landscapes. The binomial acceptance/correlation becomes particularly central when pre-existing and new material/immaterial components interact with the new emerging qualities of resilience, inclusion and vitality required by the built habitat. In fact, these latter conditions deal not only with the needs and with necessities expressed directly by inhabitants, but also represent conditions to be introduced by the design of El within the socio-organisational, spatial, and bioecological components of settlement systems [28].

To achieve this, El must become part of a process of trans-scalar intervention that connects strategicprogrammatic aspects with tactical scenarios and operational aspects [29]. This process requires at least three methodological innovations involving:

- the possibility to strategically rethink $\mathrm{EI}$ as infrastructures no longer based on monofunctional, restricted and dedicated/exclusive models. In practical terms El must be analysed and investigated as technological-environmental systems based on a cross-over model, able to restore connections between users, the energies of the territory, physical entities and factors of context at both the territorial level (Territorial Interface Areas, such as reservoirs and vast areas) and at the urban level (Urban Interface Areas, such as axes, intersections and edges);

- the need to identify qualitative conditions and macro-requirements for $\mathrm{El}$ at the tactical level, referred not only to specific and precise technical aspects. The concept of quality must be reinterpreted in relational terms, seeking to promote and develop the capacity to enable new activities, functions and points of interaction at the territorial level (Territorial Interface Units that are natural, semi-natural, rural, rurban, suburban and urban) and at the urban level (Urban 
Interface Units such as streets, plazas, green fields, brown fields, residual spaces);

- the opportunity to redefine technical-constructive solutions for El at an operational level that are not closed and irreversible actions. This delineates the possibility to incorporate integrative solutions able to promote existing resources and generate additional new resources at the territorial level (Territorial Interface Sub-Units such as nodes, corridors, functional and/or hybrid spots and networks) and at the urban scale (Urban Interface Sub-Units that include connections and relations between the street, building, earth, and sky).

This change in the vision of infrastructural interventions for energy would produce the fundamental innovative result of repositioning design technologies at a tactical, intermediate and relational level. This is a level at which to establish a dialogue and convergence between strategic decisions (in the case of El assumed today at an exclusively at the level of top-down planning) and implementational actions (which have dealt only with technical-executive aspects from the bottom-up).

The tactical dimension of this level permits an evaluation of $\mathrm{El}$ in relation to multiple scenarios centred on the comprehension of the energy cycles affecting the entire habitat.

\section{Technological Scenarios for El: Four Hypotheses for the Territory of Abruzzo, Italy}

There are multiple scenarios for reconsidering El as systems of technological-environmental interfaces able to foster the reconnection between energies and landscape.

The present paper looks at four scenarios that, while certainly not exhaustive, are congruent with the conceptual and methodological considerations explored above. These scenarios were examined in studies and research developed in recent years at the G. d'Annunzio University of Chieti-Pescara in specific areas of the region of Abruzzo. The proposed scenarios identify $\mathrm{El}$ as possible solutions for dealing with critical issues (climatic, economic) unfolding across the globe due to the increasingly more complex and conflictual relationship between processes of globalisation and specific local realties. They reflect a broader convergence between the reorganisation of the energy sector, green infrastructures, and the regeneration of settlement-production across the territory, required to deal with current processes of deindustrialisation, the economic-financial crisis of 2008 and more recent migratory emergencies.

\section{Scenario 1: Energy Routes}

The scenario of Energy Routes (ER) reconsiders the binomial tourism-culture, now one of the principal political axes of territorial development, for re-launching local economies in crisis and their progressively more competitive repositioning within the EuroMediterranean and international situation. An ER infrastructure serves to redefine shared models for the production, management, and consumption of energy resources in order to mature a responsible approach to issues of energy-environmental sustainability among inhabitants. It also serves to nurture local production and supply chains that in part conserve traditional methods of procuring energy and, in part, exploit new technologies using renewable resources (Figure 2).

At the strategic level, for an ER it is fundamental to begin with existing mobility infrastructures (roads, drovers' roads, thematic itineraries) located in foothills, hilly or coastal areas, and valley bottoms or along ridge tops in which to integrally reconsider mobility in terms of alternative and inclusive accessibility.

At the tactical level, an ER must satisfy macrorequirements of attractiveness, hospitality, accessibility, complementarity and communicability in order to guide the quality of interventions involving buildings and infrastructures and characterise sites of intervention as the hubs of a network of interactions at the territorial scale.

At the operational level, it is possible to hypothesise grid-connected or grid-off interventions for an ER (energy islands, micro-plants/micro-networks for shared energy) located in towns, villages, and minimal settlements [30].

\section{Scenario 2: Hybrid Rural Infrastructures}

In the medium-term and long-term, the mechanisms for stimulating installations of new technologies of renewable energy production risk triggering a consumerist drift centred on large facilities, attractive for their financial profits, though highly critical for their effects above all on the rural territory (consumption of land, degradation of the landscape).

The scenario of Hybrid Rural Infrastructures (HRI) contrasts large renewable energy facilities with an 

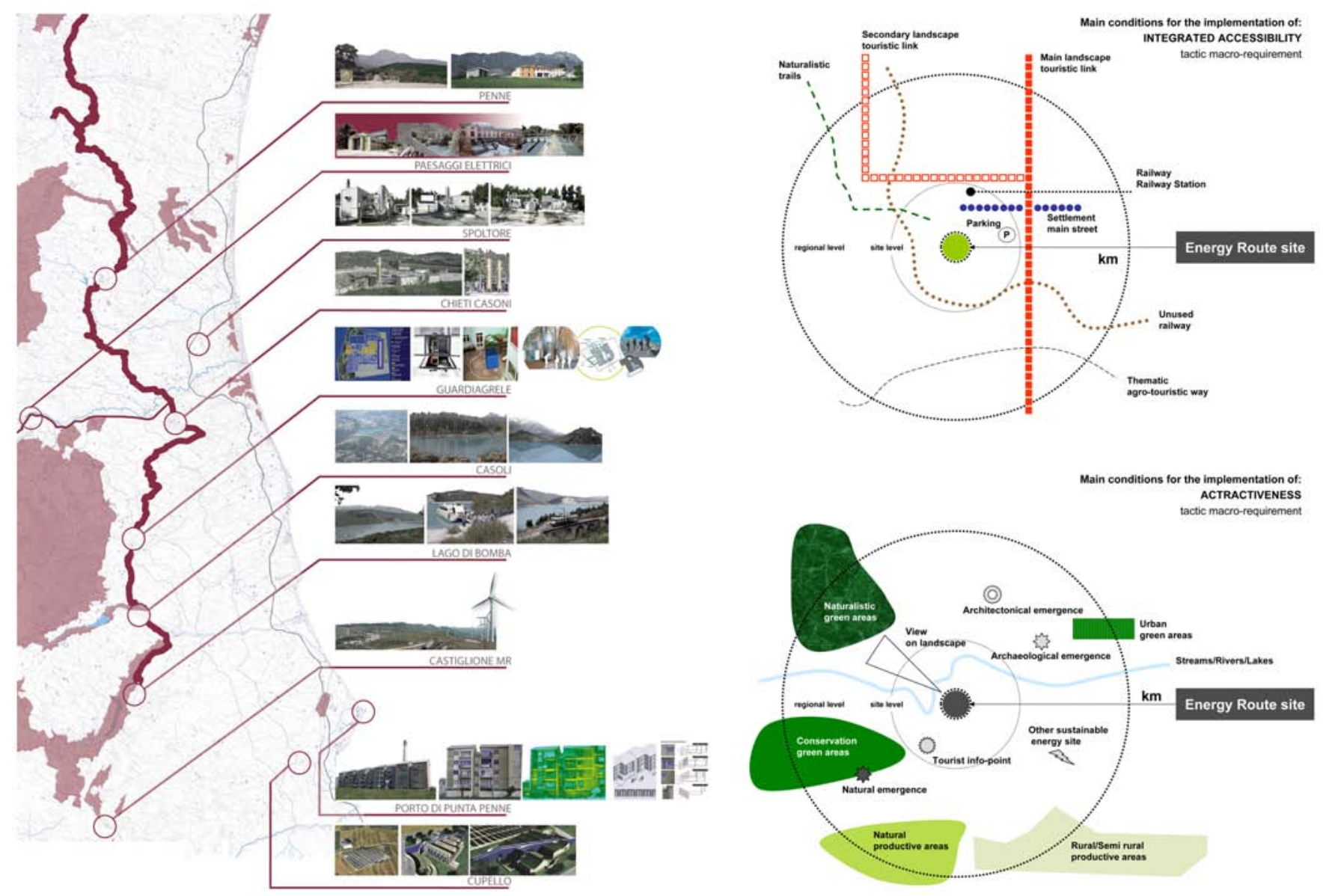

Figure 2: The Energy Route scenario. Impact of tactic macro-requirements for the selection of the Enerwood Energy Route sites in the Abruzzo region. Source: Enerwood/G. d'Annunzio University of Chieti-Pescara; Author: F. Angelucci.

alternative model of localised and diffuse microgeneration. El systems create a hybrid with other preexisting infrastructural networks and structure the agricultural landscape to reinforce the energy ties between producers and consumers, breaking free of logics that return surplus energy to the unified network (Figure 3).

At the strategic level, the implementation of an HRI must consider pre-existing infrastructures (ecological, hydro-geological, transport) located in rural, urban and suburban areas, privileging models based on a mix of technologies for localised micro-generation.

At the tactical level, HRI must satisfy macrorequirements of heterogeneity, connectivity, coevolution, correlation, and cyclicity to redirect rural productive areas toward models of autonomy and the sharing of energy resources.

At the operational level, HRI may consist of hybrid networks that introduce functions of renewable energy generation into infrastructures of distribution, water regimentation, ecological reconnection, soil reinforcement, and slow mobility.

\section{Scenario 3: The Near Zero KM Community}

While it is true that high-speed railway lines are helping re-launch the competitiveness of rail-based transport, they are also increasing the decommissioning and abandonment of countless kilometres of existing rail lines that contributed to the definition, formation and evolution of the modern agrarian and industrial landscape.

The scenario of the Near Zero KM Community (NZKC) pursues the hypothesis of transforming decommissioned railway lines into El. Other than favouring slow/alternative mobility, they also enable operators in the Zero KM food sector to interact (transport, exchange, exhibit, taste) more effectively in urban, suburban and urban areas (Figure 4).

At the strategic level NZKC require a reconsideration of decommissioned railway lines as multifunctional socio-economic connectors crossing the 


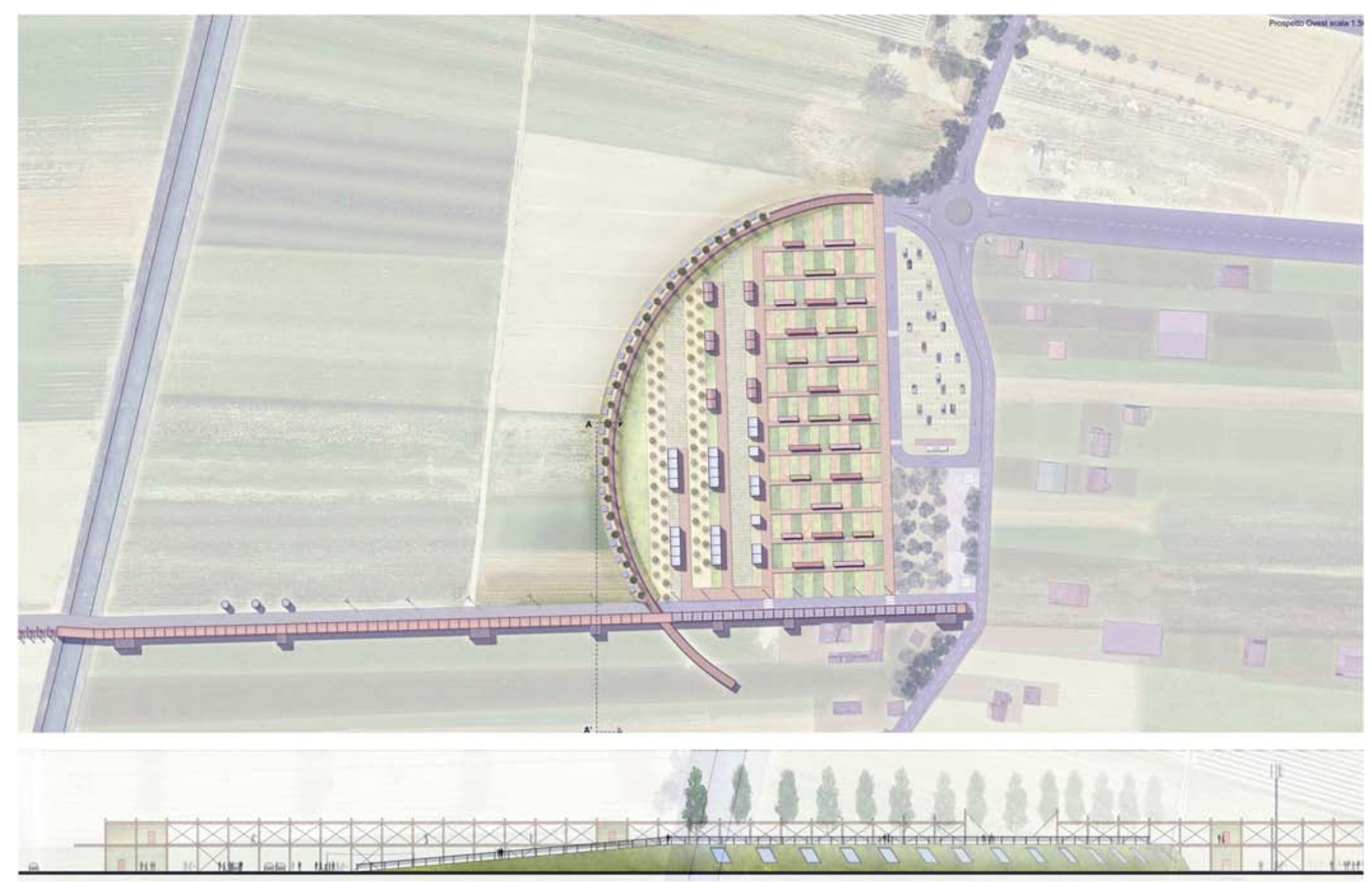

Figure 3: The Hybrid Rural Infrastructure scenario. Example of integrated IE system in Abruzzo agricultural landscape.

Source: Master degree thesis "Scenari tecnologici per la piana del Fucino: due ipotesi di intervento per il territorio agricolo di Celano”, G. d'Annunzio University of Chieti-Pescara, author, F. Aveani; tutor, F. Angelucci.

principal areas for procuring and supplying food to urbanised settlements.

At the tactical level, NZKC must satisfy macrorequirements of correlation, integrated accessibility, hospitality, complementarity, adaptability, and transformability in order to redefine decommissioned railway lines as condensers of the energies of new communities of inhabitants with a low ecological footprint.

At the operational level, NZKC are based on the reuse/restoration/regeneration of decommissioned railway hardware (tracks, power lines, crossing boxes, stations) to reactivate functions related to alternative mobility (bicycle, pedestrian, tram-train). They provide new interventions that promote local food production and enable the birth of new Zero KM communities of consumers/producers [31].

\section{Scenario 4: The Near Zero Energy Community}

The scenario of the Near Zero Energy Community (NZEC) is to some degrees complementary that of
NZKC. It remains based on the recovery of decommissioned rail lines, though it is more directly oriented toward the production of renewable energies. An NZEC is an El that:

- aids the convergence of localised and diffuse production of clean energy;

- $\quad$ regenerates the interstitial and residual spaces of the industrial city [32];

- $\quad$ recovers the unproductive areas in a territory;

- integrates technological innovations for the production of renewable energy as part of a unified project for private, public and collective spaces [33];

- reactivates railway infrastructures to favour alternative mobility and provided interventions that favour modal interchanges (Figure 5).

At the strategic level, the activation of NZEC must work with decommissioned railway infrastructures 

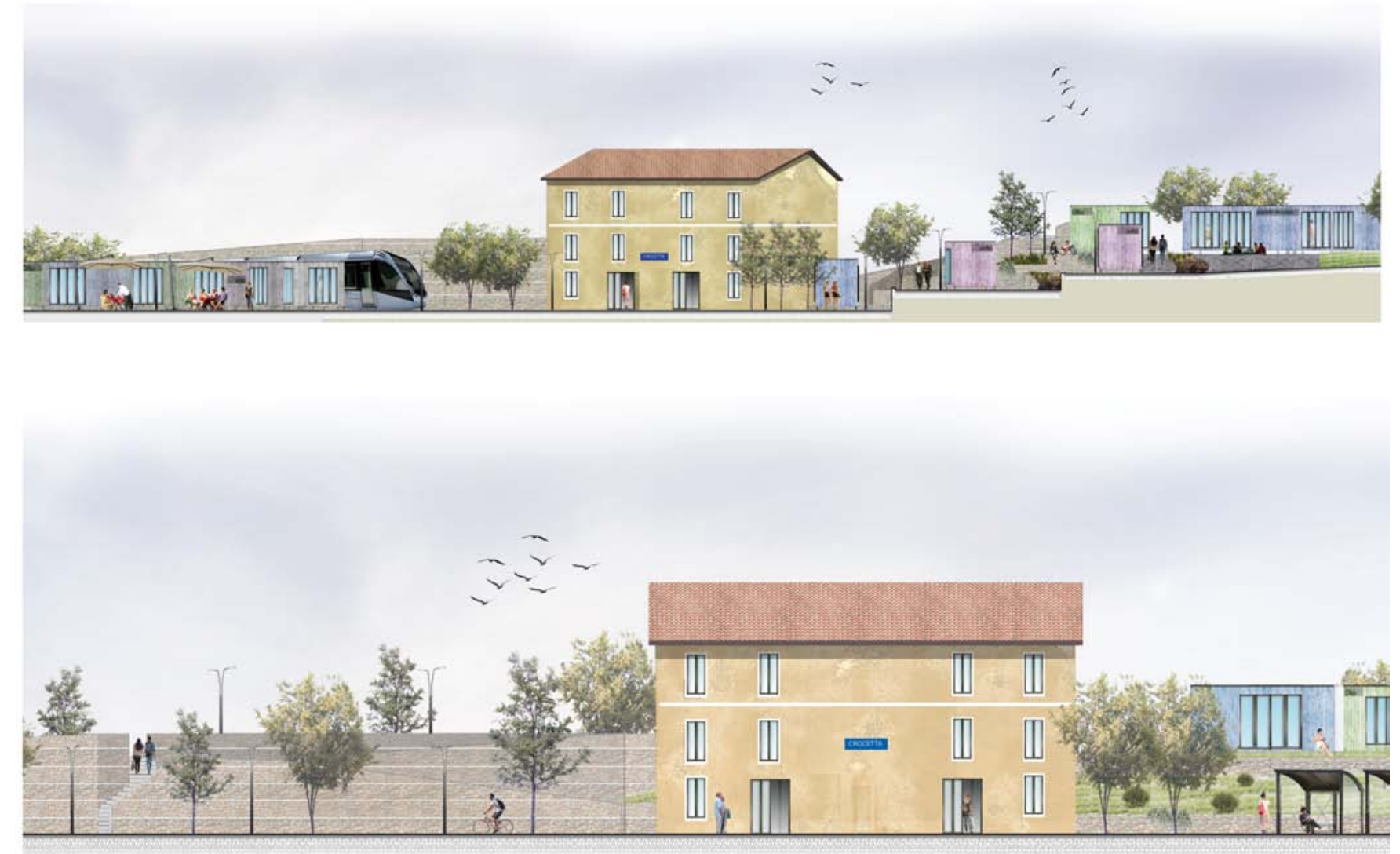

Figure 4: The Near Zero Kilometers Community scenario. Analysis of local products availability and hypothesis for a zero $\mathrm{km}$ food market along the decommissioned Sangritana railway.

Source: Master degree thesis "Paesaggi tecnologici e infrastrutture verdi per la mobilità. Ripensare l'ex ferrovia Sangritana per una Nearly Zero Kms Food Community", G. d'Annunzio University of Chieti-Pescara, author, S. Ruberto; tutor, F. Angelucci.

located in natural, rural or urban areas, in which to stimulate the formation of settlements whose energy consumption is close to zero.

At the tactical level, NZEC must satisfy macrorequirements of productivity, profitability, connectivity, transformability, adaptability and integrated accessibility to coordinate interventions involving open space and buildings toward the shared objective of a zero energy community.

At the operational level, NZEC must deal in particular with the regeneration of in-between spaces situated between railway infrastructures, the city and nature in order to redefine them as new inclusive spaces of socialisation/creativity and as platforms for the production and sharing of energy.

\section{CONCLUSIONS}

Reconsidering energy infrastructures as technological-environmental artefacts that not only generate/transport energy, but also condense multiple functions and roles, serving as an interface between various components of the manmade environment, may delineate an important horizon of innovation for the evolution of contemporary landscapes in transition.

There is a tendency to overcome the romantic and modern definition of the landscape, imagined, designed and constructed in parts, emerging elements or zones based on precise architectural-scenographic definitions. The landscape is no longer the sum of distinct events or a collection of concentrations of quantity. It is now an energy landscape [34], a system whose various resources and energies generate differences in potential, tensions and, dynamic equilibriums, in a diffuse matrix of built interventions of quality.

In this energy landscape technological responses must be capable not only of explicating levels of efficiency and performance, but also of re-orienting, recomposing and governing the complexity of transformations realised to date. They must guarantee the conservation, care, and continuous regeneration of 

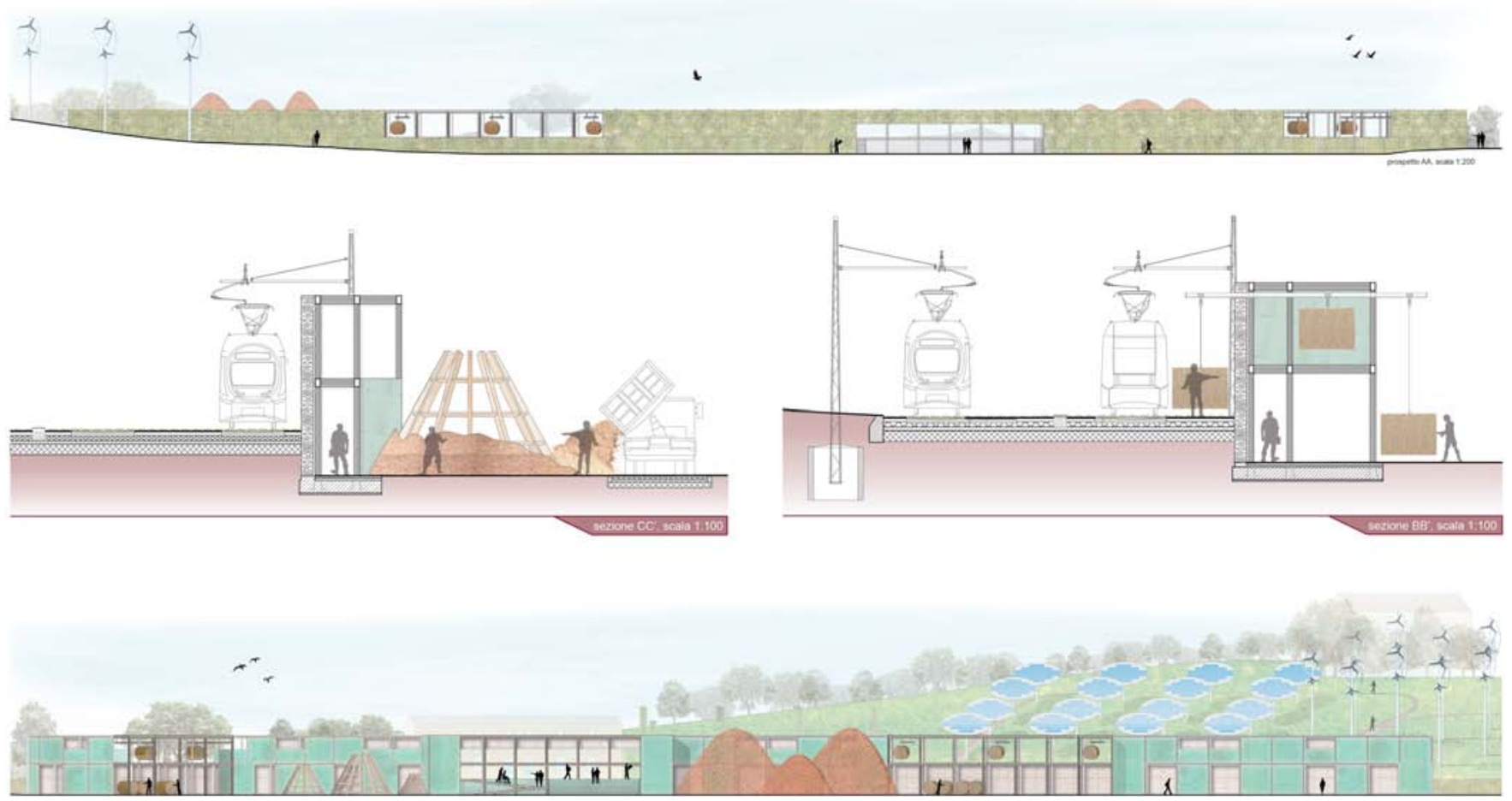

Figure 5: The Near Zero Energy Community scenario. Analysis of renewable energy resources (solar, wind, biomass) and hypothesis for an integrated production center along the decommissioned Sangritana railway.

Source: Master degree thesis "Paesaggi tecnologici e infrastrutture verdi per la mobilità. Ripensare l'ex ferrovia Sangritana per una Nearly Zero Energy Community", G. d'Annunzio University of Chieti-Pescara, author, G. Coluccia; tutor, F. Angelucci.

environmental resources and enable users to develop responsible behaviour and practices toward the local cultural-historic, morphological-naturalistic and aesthetic-perceptive characteristics of the territory.

In this direction, energy infrastructures may assume a determinant role in dealing with current and future environmental emergencies (energy, climate, resources, waste, pollution). El have the potential to become infrastructures for overcoming the traditional model of producing/consuming energy (from nonrenewable resources, centralised/concentrated) and the beginning of new decentred, shared, and diffuse forms of micro-production using renewable resources. At the same time, however, they may also assume the role of infrastructures of transition, condensers of comparison, experimentation and implementation of technological-environmental innovations for a developing landscape in which to reconstruct lost relations between the environment, transportation, culture, tourism and, wellbeing of inhabitants.

\section{REFERENCES}

[1] Angelucci $F$, Introduzione. La costruzione del paesaggio energetico. In: Angelucci $F$, editor. La costruzione del paesaggio energetico. Milano: Franco Angeli 2011; pp. 1729.
[2] Bonesio L, Geofilosofia del paesaggio. Milano: Mimesis 1997.

[3] Dierna S, Pianificazione e controllo dei processi di trasformazione ambientale. Paesaggio urbano 1993; pp. 516.

[4] Pallante M, Exiting the destructive spiral of innovation. In: Life in the Balance, Proceedings of XXXII edition of International Study Pio Manzù; 2006: Rimini, Italy: International Research Centre Pio Manzù 2006; vol 2: pp. 33-44.

[5] Pavia R, II passo della città. Temi per la metropoli futura. Roma: Donzelli 2015.

[6] Stremke S, Sustainable Energy Landscape: Implementing Energy Transition in the Physical Realm. In: Encyclopedia of Environmental Management. London/New York: Taylor \& Francis 2015. https://doi.org/10.1081/E-EEM-120053717

[7] Sijmons D, Past Present and Future. In: Sijmons D, Landscape and Energy. Designing Transition. Rotterdam: Nai 010 Publishers 2014; pp. 24-85.

[8] Bonomi A, Le metamorfosi dei territori. Da Piero della Francesca alla smart city. In: Bonomi A, Masiero R, Dalla smart city alla smart land. Venezia: Marsilio 2014; pp. 13-70.

[9] Walker B, Holling CS, Carpenter S, Kilzig, Resilience, Adaptability and Transformability in Social ecological Systems. Ecology and Society 2004 n.9 (2); https://doi.org/10.5751/ES-00650-090205

[10] CSIRO, Arizona State University and Stockholm University, Urban Resilience Research Prospectus. A Resilience Alliance Initiative for Transitioning Urban Systems towards Sustainable Futures, Stockholm: Resilience Alliance 2007.

[11] Reed C, Projective Ecologies. In: REDS. Rome Ecological Design Symposium. Roma: LIST Monograph. IT 2013; pp. 336-338. 
[12] Ove ARUP \& Partners, Rockefeller Foundation, City Resilience Framework. New York/London: The Rockefeller Foundation/ARUP 2014.

[13] Angelucci F, Di Sivo M, Ladiana D, Responsiveness, Adaptability, Transformability: the new quality requirements of the built environment. Techne. Journal of Technology for Architecture and Environment. $2013 \mathrm{n}^{\circ} 05 / 2013$. Firenze: Firenze University Press; pp. 53-59; available from: http://www.fupress.net/index.php/techne/article/view/12801.

[14] World Health Organization, ICF. International Classification of Functioning Disabilities and Health, Geneve: Erickson 2006; pp. 9-28.

[15] Malcevschi S, Green Infrastructures and ecological reconstruction in urban and peri-urban areas. Techne. Journal of Technology for Architecture and Environment. $2016 n^{\circ} 11 / 2016$. Firenze: Firenze University Press; pp. 3339; available from: http://www.fupress.net/index.php/ techne/article/view/18398/17105

[16] Droege P, La città rinnovabile. Guida completa ad una rivoluzione urbana. Milano: Edizioni Ambiente 2008.

[17] Landry C, The Art of City Making. London: Taylor \& Francis Ltd 2006.

[18] Rifkin J, The Zero Marginal Cost Society. The Internet of Things, the Collaborative Commons, and the Eclipse of Capitalism. New York: Palgrave Macmillan 2014; Chapter IX and XII.

[19] Vittoria E, Argomenti per un corso di tecnologia dell'architettura. Roma: Multigrafica Brunetti 1975; p. 13-22.

[20] Ciribini G, Ed. La normativa dell'impatto ambientale. Piano di fattibilità. Firenze: Alinea Editrice 1990; pp. 9-22.

[21] Spadolini PL, Civiltà industriale e nuove relazioni nel territorio. In: Gurrieri F, editor, Pierluigi Spadolini. Umanesimo e tecnologia. Milano: Electa 1988; pp. 260-275.

[22] Mulder K, The Technological Landscape. In: Sijmons D, Landscape and Energy. Designing Transition. Rotterdam: Nai 010 Publishers 2014; pp. 368-380.

[23] European Commission, Communication from the Commission to the European Parliament, COM (2013) 249, final: Green Infrastructure (GI)/Enhancing Europe's Natural Capital, Technical information on Green Infrastructure". Brussels: CE Publishing 2013.
[24] Malcevschi S. Infrastrutture verdi e buone pratiche. In: Valutazione Ambientale 2013 n.24/2013. Edicom Edizioni, Monfalcone 2013; pp. 21-31.

[25] Ahern J, Green infrastructure for cities: The spatial dimension. In: Novotny $\mathrm{V}$, Brown $\mathrm{P}$, editors, Cities of the Future Towards Integrated Sustainable Water and Landscape. London: IWA Publishing 2007.

[26] European Commission, European Landscape Convention Firenze: Council of Europe 2000.

[27] Desideri P, Leviathan. In: Desideri P, editor, Ex City. Roma: Meltemi 2001; pp. 8-39.

[28] Clementi A, L'ipotesi EcoWebTown. In: Clementi A, Forme imminenti. Città e innovazione urbana. Rovereto: List Lab 2016; pp. 192-215.

[29] Schiaffonati $F$, The territory of infrasctructures. Techne. Journal of Technology for Architecture and Environment. $2016 n^{\circ} 11 / 2016$. Firenze: Firenze University Press; p. 12-21; available from: http://www.fupress.net/index.php/techne/ article/view/18395

[30] Angelucci F, La connessione cultura turismo energia per la riconfigurazione dell'habitat. In: Angelucci F, editor. La costruzione del paesaggio energetico. Milano: Franco Angeli 2011; pp. 129-136.

[31] Angelucci F, Fast, Slow, Crossover Railways. Technological Scenario for the Reuse of Abandoned Railways. In: Agribusiness Paesaggio \& Ambiente. Vol. XVI - $n^{\circ} 1$, Mar 2013.

[32] Angelucci F. Heterotopias of Urban In-Betweens. Renewing Cities and Rediscovering the Vitality and Resilience of Open Spaces. In: Agribusiness Paesaggio \& Ambiente. Vol. XVIII $\mathrm{n}^{\circ} 1$, Mar 2015

[33] Tucci F, Design, technology, energy quality of building and living in Nearly zero energy and zero emission architecture. In: Lucarelli MT, Mussinelli E, Trombetta C, editors, The Architectural technology network for innovation. Rimini: Maggioli Editore 2016; pp. 68-79.

[34] Angelucci $F$, Costruire il paesaggio secondo una visione energetica. In: Angelucci $F$, editor. La costruzione del paesaggio energetico. Milano: Franco Angeli 2011; pp. 6578.

\section{DOI: http://dx.doi.org/10.6000/1929-6002.2016.05.04.4}

(c) 2016 Filippo Angelucci; Licensee Lifescience Global.

This is an open access article licensed under the terms of the Creative Commons Attribution Non-Commercial License (http://creativecommons.org/licenses/by-nc/3.0/) which permits unrestricted, non-commercial use, distribution and reproduction in any medium, provided the work is properly cited. 